front of the stars they orbit. So far, after barely a year of observations, Kepler is limited to detecting short-period planets, those close to their stars.

The new-found planet orbits its star - designated Kepler 10 - every 20 hours, at a distance of 2.5 million kilometres. This is less than $2 \%$ of the distance separating Earth and the Sun, ensuring that the planet is more 'terra lava' than terra firma, with a surface temperature of $1,800{ }^{\circ} \mathrm{C}$, hot enough to melt silicate rock.

Astronomers at Keck were able to monitor how the planet tugs on the star, giving them its mass. Meanwhile, because the star is nearer than most of the stars in Kepler's search field, the Kepler

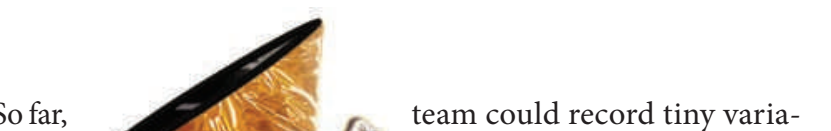
tions in the star's luminosity due to sound waves rippling through its interior. The timing of these acoustic oscillations provided detailed information about the star's dimensions, much as the sound of a string on a bow reveals whether the instrument being played is a violin or a cello.

"Everything we measure about the planet is relative to the parent star," says Batalha. Armed with a precise figure for the star's diameter, she and her colleagues were able to nail down the planet's dimensions with similar precision.

The planet's close orbit is similar to that of another rocky exoplanet, CoRoT-7b, discovered in 2009, says Greg Laughlin, an astronomer at

the University of California, Santa Cruz, who 䍃 was not involved in the work. He says the result $\frac{\pi}{z}$ shows how far astronomers' techniques for

The first confirmed rocky planet to fall within Kepler's sights is an encouraging sign for the mission.

Laughlin. Their existence suggests that cooler smaller worlds await discovery as Kepler's monitoring time increases and it can identify planets in longer, more distant orbits, he adds.

In February, the Kepler mission is expected to release data on 400 additional planetary candidates. The team is excited, says Batalha, because it hopes that Kepler's growing number of detections will offer the first concrete estimates of the frequency of extrasolar planets rocky and otherwise. "So far, it's been a deluge," says Batalha. "And we look forward to finding a lot more planets." -

\section{Drought-tolerant maize gets US debut}

\section{Seed companies race to tap multibillion-dollar market.}

\section{BY JEFF TOLLEFSON}

$\mathrm{W}$ hen the planting season arrives later this year, farmers in the United States will have a new way to safeguard their crops from drought. Last week, DuPont subsidiary Pioneer Hi-Bred International, headquartered in Johnston, Iowa, announced plans to release a series of hybrid maize (corn) strains that can flourish with less water. The seeds will compete with another maize strain unveiled last July by Swiss agribusiness Syngenta. Both companies used conventional breeding rather than genetic engineering to produce their seeds. new hybrids will increase maize yields by $5 \%$ in water-limited environments, such as the western states of the intensively agricultural Corn Belt region. That compares with the $15 \%$ yield gain promised by Syngenta for its maize. Both companies, as well as seed firm Monsanto, based in St Louis, Missouri, are also working on transgenic maize varieties, hoping to tap into a multibillion-dollar market (see Nature 466, 548-551; 2010).
Pioneer says that field studies show its
In theory, drought-tolerant varieties could fill the gap left in maize supplies in recent years as stocks have been diverted for ethanol production. But not everybody is convinced that these crops will make a big difference. "It's good news, but it's not great news," says David Zilberman, an agricultural economist at the University of California, Berkeley. No crop will survive a severe drought, he says, and other factors such as nutrient availability and soil quality are at play during water shortages, which tend to be more frequent but less severe than droughts. "It will be useful for a small number of really important areas," Zilberman says, "but my feeling is that people expect altogether too much from drought tolerance."

Creating drought-tolerant plants has proved to be a difficult challenge for plant breeders. Whereas resistance to a particular herbicide might be pinned down to one gene, the response to drought plays out across the genome. A plant's resilience also depends on when drought strikes - early or late in the life cycle, for instance - and on which nutrients
ONATURE.COM For Nature's recent food special, see: nature.com/food are available. Moreover, varieties that perform better when thirsty often underperform when water is plentiful. The industry researchers identified thousands of genes associated with drought tolerance, then incorporated them into their hybrids through conventional breeding. "All of this technology has just come together beautifully in the past ten years," says Jeff Schussler, senior research manager at Pioneer.

The new varieties will be marketed only in the United States, but efforts to develop drought-tolerant maize are also under way in Africa and Asia. Working with the Bill \& Melinda Gates Foundation and other donors, international agricultural research centres have already introduced dozens of conventional drought-tolerant varieties into 13 of the most important maize-producing countries in subSaharan Africa. These new varieties now make up $15-25 \%$ of the 19 million hectares of maize planted in these countries each year, according to Marianne Bänziger, deputy director-general for research and partnerships at the International Maize and Wheat Improvement Center (CIMMYT) in Mexico City. A recent study by CIMMYT and its partners suggests that the new varieties could increase yields by $10-34 \%$.

The big seed companies are also contributing expertise. Last year, South Africa was home to the first field trial for a transgenic droughttolerant maize crop, incorporating a gene from the variety currently under development by Monsanto. Meanwhile, CIMMYT recently partnered with the Syngenta Foundation for Sustainable Agriculture, based in Basel, Switzerland, to expand its drought-tolerant maize programme. "Within five years, we hope to have crops in Asia," Bänziger says. - 